\title{
General practitioners' responsibilities to their patients
}

\author{
Michael Whitfield, Romola Bucks
}

\begin{abstract}
The views of general practitioners about their responsibilities for patient care have not been canvassed. A survey of general practitioners was therefore carried out to determine their views. A postal questionnaire, in which general practitioners were asked what they saw as their responsibilities, was sent to 525 principals in Avon and completed by 424 , giving a response rate of $81 \%$. The doctors generally agreed that their responsibilities for patient care included problems related to internal medicine, such as managing diabetes and hypertension. Less consensus was found in the replies to questions about technical procedures, such as resection of ingrowing toenails, and gynaecological, orthopaedic, or psychosocial problems.

The results supported the view that general practitioners' are gradually abandoning technical aspects of medicine to specialists without a compensating role having been defined. In the light of this trend the responsibilities of general practitioners should be clearly defined by the profession.
\end{abstract}

\section{Introduction}

Little is known about the range of tasks undertaken by general practitioners; though their rates of referral to specialists, how often they issue prescriptions, the number of investigations they perform, and the number of recall consultations they have are known to vary considerably.' According to Cartwright, the amount of what general practitioners perceive as "trivial consulting" also varies appreciably.". Substantial evidence suggests that general practitioners vary in their willingness to manage psychological and social problems, ${ }^{+5}$ although their views on the range of their responsibilities for patient care have not previously been sought.

Ideas on how to improve the primary health services were recently published by the government ${ }^{t}$; clearly it is important that these improvements should not conflict with general practitioners' views about their role in patient care. As part of a larger study of general practitioners' attitudes we asked doctors in Avon about their perceived responsibilities for patient care in a questionnaire based on one previously used in a study of Dutch general practitioners.

General Practice Unit, Department of Epidemiology and Community Medicine, University of Bristol, Bristol BS8 2PR Michael Whitfield, FRCGP, consultant senior lecturer Romola Bucks, BSC, research assistant

Correspondence to: Dr Whitfield.

\section{Subjects and methods}

In May 1987 we sent all 525 general practitioners having a contract with Avon Family Practitioner Committee a postal questionnaire, in which they were asked to state whether they thought that certain tasks were the responsibility of general practitioners by showing whether they believed that the tasks were totally, often, sometimes, seldom, or not at all their responsibility. We sent one reminder to practitioners who did not respond, and $424(81 \%)$ questionnaires were returned. General practitioners whose practices were on the edge of the area covered by the family practitioner committee and had few patients within the area were excluded, as were doctors with limited responsibilities, such as those caring only for students and patients in hospices ( 53 respondents).

For analysis we divided the questions into two groups, concerning medical and psychosocial problems. The questions on medical care were divided into four sections: traditional medical problems such as treating diabetes and hypertension, technical problems such as aspirating knee effusions and inserting intrauterine devices, gynaecological problems such as treating menorrhagia, and orthopaedic problems such as diagnosing a fracture. The questions on psychosocial care were divided into three sections: traditional medical tasks such as caring for dying patients and their families, psychosocial tasks such as treating mild agoraphobia, and the rather more difficult psychological problems of offering help for problems of addiction and sexual therapy and relaxation therapy for complaints related to stress.

\section{Results}

Three hundred and seventy one doctors $(79 \%$ of those eligible) comprised the study sample. The doctors who did not reply to the questionnaire were similar to those who did in terms of age, sex, size of list, and position in the practice. Of the few doctors $(27$, $6 \%$ ) in singlehanded practice in Avon, only 11 (41\%) responded.

Traditional medical problems-Most doctors thought that general practitioners were responsible either always or often for caring for patients with traditional medical problems including moderate hypertension, non-insulin dependent diabetes, mild to moderate rheumatoid arthritis, psoriasis, angina pectoris, stroke, chronic obstructive airways disease, heart failure, and superficial thrombophlebitis of the leg (table I). Treatment of superficial thrombophlebitis of the leg is rarely carried out by specialists and, not surprisingly, $58 \%$ (213) of the doctors considered this to be their sole responsibility whereas they were apparently prepared to share the care of the other traditional medical problems. There were no significant differences in age among the doctors giving particular responses.

Technical problems-A wide range of opinions were expressed about general practitioners' responsibilities for intrapartum care, wedge resection of ingrowing toenails, aspiration of knee effusions, and insertion of intrauterine devices (table II). Intrapartum care is increasingly the responsibility of specialists, and our results showed that older general practitioners tended much more than younger ones to think that it should be the general practitioners' responsibility (KruskalWallis test, $p \leqslant 0.001)$. Most thought that insertion of intrauterine devices was their responsibility. Surgeons 
and rheumatologists have not generally made claims to take over wedge resection of ingrowing toenails or aspiration of knee effusions, yet opinions about the responsibility for these procedures varied widely among the general practitioners.

Gynaecological problems-Except for establishing the cause of subfertility, which only $17 \%(61 / 369)$ of doctors thought to be their responsibility, most doctors considered gynaecological care to be their responsibility (table III). Young doctors were more prepared to consider diagnosing the cause of subfertility to be their responsibility than older doctors (Kruskal-Wallis test, $\mathrm{p} \leqslant 0.001$ ).

TABLE 1-Responsibility for treating traditional medical problems. Figures are numbers (percentages)

\begin{tabular}{lrlcccc}
\hline & Totally & Often & Sometimes & Seldom & Not at all & Total \\
\hline $\begin{array}{l}\text { Moderately serious hypertension } \\
\quad \text { diastolic pressure 110-120 mm Hg) }\end{array}$ & $168(45)$ & $178(48)$ & $21(6)$ & $3(1)$ & & 370 \\
Non-insulin dependent diabetes & $128(35)$ & $218(59)$ & $20(5)$ & $5(1)$ & & 371 \\
Mild to moderate rheumatoid arthritis & $80(22)$ & $228(61)$ & $54(15)$ & $8(2)$ & 1 & 371 \\
Psoriasis & $32(9)$ & $297(8)$ & $39(11)$ & $3(1)$ & & 371 \\
Angina & $43(12)$ & $311(84)$ & $16(4)$ & & & 370 \\
Stroke & $7(2)$ & $246(66)$ & $108(29)$ & $8(2)$ & $2(1)$ & 371 \\
Chronic obstructive airways disease & $55(15)$ & $304(82)$ & $11(3)$ & 1 & & 371 \\
Heart failure & $56(15)$ & $300(81)$ & $13(4)$ & 1 & & 370 \\
Superficial thrombophlebitis of leg & $213(58)$ & $147(40)$ & $7(2)$ & & & 367 \\
\end{tabular}

TABLE II-Responsibility for technical tasks. Figures are numbers (percentages)

\begin{tabular}{lrrrrrr}
\hline & Totally & Often & Sometimes & Seldom & Not at all & Total \\
\hline Wedge resection of ingrowing toenail & $50(14)$ & $65(18)$ & $94(25)$ & $87(24)$ & $74(20)$ & 370 \\
Intrapartum care & $9(2)$ & $88(24)$ & $94(25)$ & $105(28)$ & $74(20)$ & 370 \\
Aspiration of knee effusion & $29(8)$ & $77(21)$ & $138(37)$ & $76(21)$ & $50(14)$ & 370 \\
Insertion of intrauterine device & $149(40)$ & $161(43)$ & $31(8)$ & $9(2)$ & $21(6)$ & 371 \\
\hline
\end{tabular}

TABLE III-Responsibility for gvnaecological problems. Figures are numbers (percentages)

\begin{tabular}{lcccccc}
\hline & Totally & Often & Sometimes & Seldom & Not at all & Total \\
\hline $\begin{array}{l}\text { Diagnosis of cause of subfertility } \\
\text { Treatment of vaginal prolapse with }\end{array}$ & $2(1)$ & $59(16)$ & $144(39)$ & $120(33)$ & $4(12)$ & 369 \\
$\begin{array}{l}\text { pessary } \\
\begin{array}{c}\text { Treatment of menorrhagia at } \\
\text { menopause }\end{array}\end{array}$ & $89(24)$ & $156(42)$ & $82(22)$ & $32(9)$ & $11(3)$ & 370 \\
& $25(7)$ & $242(65)$ & $76(21)$ & $16(4)$ & $11(3)$ & 370
\end{tabular}

TABLE IV-Responsibility for diagnosis of orthopaedic problems. Figures are numbers (percentages)

\begin{tabular}{lcccccc}
\hline & Totally & Often & Sometimes & Seldom & Not at all & Total \\
\hline Torn knee cartilage & $30(8)$ & $163(44)$ & $133(36)$ & $29(8)$ & $13(4)$ & 368 \\
Fracture & $20(5)$ & $158(43)$ & $133(36)$ & $47(13)$ & $12(3)$ & 370 \\
\hline
\end{tabular}

TABLE V-Responsibility for medical psychosocial problems. Figures are numbers (percentages)

\begin{tabular}{|c|c|c|c|c|c|c|}
\hline & Totally & Often & Sometimes & Seldom & Not at all & Total \\
\hline $\begin{array}{l}\text { Caring for dying patients and their } \\
\text { families }\end{array}$ & $153(42)$ & $207(56)$ & $7(2)$ & & & 367 \\
\hline Explaining hyperventilation syndrome & $168(46)$ & $158(+3)$ & $36(10)$ & $6(2)$ & & 368 \\
\hline $\begin{array}{l}\text { Explaining relation between vague } \\
\text { functional complaints and problems } \\
\text { of daily life }\end{array}$ & $159(43)$ & $19152)$ & $14(4)$ & $+(1)$ & & 368 \\
\hline Treating fear of serious disease & $89(24)$ & $248(67)$ & $30 \quad 8$ & 1 & & 368 \\
\hline
\end{tabular}

TABL.E VI-Responsibility for psychosocial problems. Figures are numbers (percentages)

\begin{tabular}{|c|c|c|c|c|c|c|}
\hline & Totally & Often & Sometimes & Seldom & Not at all & Total \\
\hline $\begin{array}{l}\text { Advising parents on problems of } \\
\text { bringing up children }\end{array}$ & $22(6)$ & $186(51)$ & $1+6(40)$ & $13(4)$ & 1 & 368 \\
\hline $\begin{array}{l}\text { Discussing problems in relationships } \\
\text { Investigating social background of }\end{array}$ & $28(8)$ & $181+49$ & $142(39)$ & $15(4)$ & $2(1)$ & 368 \\
\hline complaints & $40(11)$ & $168(46)$ & $125(34)$ & $28(8)$ & $7(2)$ & 368 \\
\hline Treating mild agoraphobia & 39 (11) & $186(50)$ & $122(33)$ & $22(6)$ & & 369 \\
\hline $\begin{array}{l}\text { Caring for discharged psychiatric } \\
\text { patients }\end{array}$ & $25 \quad(7)$ & $240(65)$ & $103(28)$ & & & 368 \\
\hline
\end{tabular}

Orthopaedic problems - In general the doctors agreed that diagnosing orthopaedic problems fell within their remit, but $133(36 \%)$ of them remained ambivalent, stating that only sometimes was the responsibility theirs (table IV).

Medical psychosocial problems-Medical psychosocial problems, including caring for dying patients and their families, dealing with fear of serious conditions such as cancer or heart attacks, and explaining the relation between vague functional complaints and the problems of daily life, were generally accepted as the responsibility of general practitioners (table V). Apart from older doctors considering themselves to be more responsible for the care of dying patients (Kruskal-Wallis test, $p=0.0155$ ) there were no significant differences related to age.

Psychosocial problems-Doctors were prepared to accept responsibility for psychosocial tasks, which included discussing with couples any problems with their relationships and treating mild agoraphobia, but not to the same degree as for medical psychosocial problems (table VI). The replies were related to the doctors' age only for advising parents about problems of bringing up children, older doctors tending to think this to be the responsibility of general practitioners (Kruskal-Wallis test, $\mathrm{p}=0.0033$ ).

Special treatment-Special treatment applied to offering help for sexual problems and problems of addiction and providing relaxation therapy for complaints related to stress. Regardless of their age most general practitioners considered giving help for sexual problems and problems of addiction to be part of their job, but $40 \%(146 / 368)$ thought that relaxation therapy to alleviate stress was seldom or not at all their responsibility (table VII).

Overall, no significant differences were seen in the replies between members and non-members of the Royal College of General Practitioners or rural and urban practitioners (Kruskal-Wallis test). The doctors' place of work as measured by Jarman score ${ }^{8}$ did not correlate significantly with their opinions about their responsibility (Spearman's rank correlation, $p>0.05)$. We had no information about hospital training before the doctors became general practitioners.

\section{Discussion}

Interpreting answers to a questionnaire that relies on a five point scale is difficult; doctors who state that they believe they are totally responsible for certain tasks may simply mean that they think the task is important rather than that general practitioners should manage it without reference to specialists. We have assumed, however, that the doctors' answers to the questionnaire meant what they said."

Avon has a population of about a million people, comprising the urban centres of Bath, Bristol, and Weston super Mare and the surrounding rural area. Compared with other large non-metropolitan family practitioner committees, that in Avon lies below the lowest quartile for the proportions of doctors aged under 65 practising alone, aged over 65 , and with lists of more than 2500 patients. It lies above the highest quartile in terms of the proportions of doctors being paid fees for vaccination and immunisation, cervical cytological screening, and insertion of intrauterine devices and other contraceptive services. General practitioners in Avon can therefore be considered to be performing well by the performance indicators that are currently used to show good practice.

The attitudes expressed by general practitioners in Avon can thus be considered to be representative of those expressed by doctors performing to a high standard in a generally pleasant part of the United 


\begin{tabular}{|c|c|c|c|c|c|c|}
\hline & Totally & Often & Sometimes & Seldom & Not at all & Total \\
\hline Help with alcohol and drug addiction & $13(4)$ & $141(39)$ & $168(46)$ & $38(10)$ & $5(1)$ & 365 \\
\hline Help with sexual problems & $13(4)$ & $159(43)$ & $166(45)$ & $27(7)$ & $3(1)$ & 368 \\
\hline $\begin{array}{l}\text { Relaxation therapy for complaints } \\
\text { related to stress }\end{array}$ & $7(2)$ & $76(21)$ & $139(38)$ & $118(32)$ & $28(8)$ & 368 \\
\hline
\end{tabular}

Kingdom. Doctors in less fortunate environments may have different attitudes to their work, although we found no evidence that doctors practising in inner city areas differed from those in rural areas.

General practitioners have a tradition that spans many generations, but recently several changes have been made in dividing responsibility for medical and psychosocial care between generalists and specialists. Not surprisingly therefore, older general practitioners held different opinions from younger doctors about their responsibilities for such tasks as intrapartum care and caring for dying patients, in which specialists participate increasingly. Generally, though, the differing responses were not related to the age of the respondents and must be due to other factors, possibly differences in personality or attitude.

Honigsbaum criticised the service provided by general practitioners in the United Kingdom, using the term clinical drift to illustrate his belief that few general practitioners now do much clinical work with their hands and that treatment of various conditions is increasingly being taken over by hospital services. ${ }^{10}$ Our results support the belief that many general practitioners do few manual tasks, in that they denied responsibility for certain fairly common technical procedures. The government intends to encourage general practitioners to retain their responsibility for minor operations by providing specific remuneration ${ }^{6}$; whether doctors will change their attitude remains to be seen.

Honigsbaum's criticism ${ }^{10}$ implies that general practitioners are passing their responsibility for certain chronic conditions such as hypertension and diabetes to the hospital service. There is some evidence that general practitioners are not good at providing this care; half of the known hypertensive patients do not have their condition controlled," and $20-40 \%$ of diabetic patients are not even receiving annual follow up checks. ${ }^{1213}$ This is not surprising when so many

general practitioners in Avon do not consider the task of managing these patients to be their total responsibility. Perhaps they have been persuaded that shared care is the appropriate way to manage chronic illness. Sharing responsibility for chronic illness may be reassuring for doctors but may not be the most efficient and effective method for patients. Our results show that, although Honigsbaum's statements have some substance, ${ }^{10}$ most general practitioners in Avon still have a wide understanding of their responsibility to their patients. Several, however, disclosed that they restricted the number of procedures they were prepared to carry out. The Royal College of General Practitioners states that there should be consistency in the range of services available to patients through general practice ${ }^{1+}$ but fails to define the range clearly. Surely it is time that a clear job definition for the general practitioner is drawn up by the profession.

We thank the general practitioners who took part in the study for their help; the staff of Avon family practitioner committee for their cooperation; and members of this department, particularly Dr Jenny King and Ms Angela Williams, for their advice. This study was supported by the Glaxo Research Fund.

1 Metcalfe D. No excuses. In: Pereira-Gray DJ, ed. The medical annual. Bristol -Wright, 1985:184-204.

2 Cartwright A. Patients and their doctors. London: Routledge and Kegan Paul, 1967

Cartwright A, Anderson R. General practice revisited. London: Tavistock, 1981.

Shepherd M, Cooper D, Brown AC, Kalton G. Psychiatric illness in general practice. 2nd ed. Oxford: Oxford University Press, 1981.

Whitfield $M J$, Winter RD. Psychiatry and general practice; results of a survey of Avon general practitioners. $\mathcal{F} R$ Coll Gen Pract 1980;30:682-6.

6 Department of Health and Social Security. Promoting better health. London HMSO, 1987 .

7 Grol R, van Eijk J, Mokkink H, et al. Taakopvatting van de huisarts en zijn handelen in de spreekkamer. Gezondheid en Samenleving 1985;6:31-40.

8 Jarman B. Underprivileged areas: validation and distribution of scores. BrMed f 1984;289:1587-92

9 Ajzen I, Fishbein M. Understanding attitudes and predicting social behavior. New Jersey: Prentice Hall, 1980.

10 Honigsbaum F. Reconstruction of general practice: failure of reform. BrMed $\mathcal{J}$ 1985;200:823-6

11 Hart JT. Coronary disease. Br.Med 7 1982;285:347-50

12 Hammersley MS, Holland MR, Walford S, Thorn PA. What happens to defaulters from a diabetic clinic? Br Med f 1985;291:1330-2.

13 Haves TM, Harries J. Randomised controlled care of routine hospital care versus routine general practice care for type II diabetes. Br Med $\mathcal{J}$ $1984 ; 289: 728-9$.

14 Royal College of General Practitioners. The front line of the health service. College response to primary health care-an agenda for discussion. London RCGP, 1987. (Report from general practice No 25.)

(Accepted 11 April 1988
The reported indisposition of the Duke of Edinburgh from drinking impure water at a foreign station gives prominence to what is perhaps the most usual and frequent source of danger in foreign and Continental travel. Many of the sanitary authorities who have looked into the question have from time to time uttered warnings to Continental travellers as to the dangers of the ordinary drinking water to be found abroad. The pollution of table water at foreign hotels and houses is due to a great variety of causes. The water-supply of foreign cities is as a rule, to which there are only few exceptions, taken from sources lamentably liable to sewage pollution, either in open streams or uncovered reservoirs, or from defective sanitation in the house-supply. A large part of the domestic supply of drinking water is, moreover, from surface wells, which are constantly liable to sewage filtration. An examination made only a few years since, of syphons of sparkling "seltzer" in a great Continental city disclosed the fact that they were horribly polluted with sewage, and that the effervescing fixed air with which they were charged only served to conceal unutterable contaminations of a most dangerous kind. Sir Henry Thompson and Dr. Herman Weber, who have both given attention to the subject, are very emphatic in their counsel to travellers to avoid ordinary drinking water abroad. The easiest and most agreeable means of avoiding the danger is the habitual use of a pure natural mineral water in lieu of the doubtful drinking water of the hotel or the private house. When the Prince of Wales went to India he took with him a large supply of the kind, and successfully avoided this risk. Another method in which safety is sought is by invariably boiling the water before drinking it. This, however, involves more trouble than many people are willing to take, and makes the table-water flat and insipid. This insipidity may be relieved by squeezing fresh lemons into the water. But for those who cannot always be bothered with the boiling-pot or troubled with performing this little domestic operation before taking a draught of drinking-water, it would be wise when travelling abroad to select as a table-water a natural mineral water of undoubted purity rather than run the risks of blood-poisoning, typhoid, and diarrhoea to which so considerable a number of travellers at present fall victims, finding death and disease where they are seeking health and pleasure. The instances of typhoid, blood-poisoning, diarrhoea, and dysentery, of which we hear this year from Italy and Egypt, are very lamentable, and for the most part avoidable.

(British Medical fournal 1888;i:1175) 